Case Report

\title{
Identification and Prioritize Strategic Directions and Initiatives of Sustainable Supply Chains Based on Reversed Logistic Through Phase Multi-Criteria Modeled
}

\author{
Sasan Ahmadi \\ Department of Industries, Islamic Azad University Gachsaran Branch, Gachsaran, Iran \\ Email address: \\ Sasijoon13710@gmail.com \\ To cite this article: \\ Sasan Ahmadi. Identification and Prioritize Strategic Directions and Initiatives of Sustainable Supply Chains Based on Reversed Logistic \\ Through Phase Multi-Criteria Modeled. Industrial Engineering. Vol. 3, No. 2, 2019, pp. 21-26. \\ doi: $10.11648 /$ j.ie.20190302.11
}

Received: January 1, 2019; Accepted: January 24, 2018; Published: December 20, 2019

\begin{abstract}
Return and renewed using of used products has changed one of the logistic important activities with early development of industries, this caused to doing rules on this basis and also increasing awareness among people for keeping living-environment and decreasing wastage. Therefore industries need strategic programming and ripple initiatives of stable securing. Therefore the aim of this research was identification and prioritize strategic directions and initiatives of sustainable supply chains based on reversed logistics through phase multi-criteria models (case study: Dena Shiraz tire industry Company). This research was done in two different phases; in first phase, standards of strategic orientations and ripple initiatives of stable securing was identified and deciphered based on reversed logistic, based on study of scientific texts and taking ideas of expert persons ( 5 basic standards and 28 secondary standards) and alighted basis of questionnaire preparation. In second phase, identified standards was prioritized through phase multi-criteria models and taking ideas of expert persons of tire industry.
\end{abstract}

Keywords: Strategic Directions, Initiatives of Sustainable Supply Chains, Reversed Logistic, Phase Multi-Criteria Models

\section{Introduction}

The upward trend in globalization and the rise of global competition in recent decades has had a dramatic impact on industries around the world, so that, Companies which manage global supply chains face a high level of complexity with a large number of suppliers in diverse socio-economic contexts and growing expectations by customers and standardization schemes to control social and environmental aspects. According to many experts, moving towards supply chain sustainability is one of the inevitable and necessary requirements of companies to achieve such goals. Today, many leading manufacturing companies have accepted the sustainability of the supply chain as a strategy to increase their global competitive power. These companies have experienced significant advances in the use of sustainable supply chain strategies [1].

On the one hand, weak pressures associated with profits and traditional economies can reduce the incentive for companies to focus on a wider part of shareholder profits in relation to sustainable activities. In today's world, issues of supply chain management and sustainability are both important issues in industry and commerce to enhance performance, and more and more scholars around the world focus on and focus on these issues [2]. In this research, the reverse logistics effects of purchasing, production and packaging (green) programs are investigated. Sustained supply chain drivers can realize reverse logistics benefits; companies can bring economic benefits to create new value. Reverse logistics relates to the return of products or packaging after use, for reuse, recycling, or modification of materials. By engaging in reverse logistics, companies can recycle remanufactured parts, and they can also dump parts that cannot be recycled. These issues can also lead to a significant reduction in cost, which can lead to greater profitability and customer satisfaction and bring benefits to the environment. Second, the study considers the strategic drivers that endanger the success of supply chain drivers. In particular, this research identifies and reviews two 
important strategic factors that have been ignored: environmental credibility and innovation (environmental innovation), both of which address environmental issues in the strategy Companies enter the business. This study provides evidence of the role of credit and the initiative of strategic orientations in the development of sustainable supply chain initiatives, as well as their bilateral effects. Both will be important to understand corporate responsiveness to environmental challenges and the provision of sustainable supply chain drivers [2-3].

The Dena Rubber Industry Complex, Shiraz, was founded in 1972 with the participation of two Japanese companies, Marubeny and Bridgestone. The company's primary products include tire, tube and flap. In 1984, with the transfer of Japanese company shares to Iranians, the name of the factory was renamed to the Dena rubber company, and now it has about 2,000 people, plus three previous products and a conveyor belts added to the company's products. The technology used in this plant is from the Bridgestone Company of Japan and the Italian Pirelli, as well as the machines used in the Mitsubishi Japan Manufacturing Plant.

In the supply chain of the manufacturing industry, most of the materials are unusable and unprotected to the consumer and can be re-imported into the supply chain with some modification, and if this is not done, they are considered as disruptions. If they are re-entering the supply chain, they are considered as reverse logistics in the supply chain. So the issue is what we can do and what factors we can consider in the production process in terms of underlying, structural and behavioral in order to be effective in realizing the reverse logistics. So, here the strategy-driven factors, such as environmental background and environmental innovation as well as sustainable supply chain factors such as green purchases, green production and green packaging, can be effective in realizing the reverse logistics. As a result, we want to rank five strategy-driven and sustainable supply chain based on reverse logistics to determine which of these factors can be more effective. Therefore, the overall objective of the research is to prioritize strategic orientation factors and sustainable supply chain initiatives based on reverse logistics through fuzzy multi-criteria models.

\section{Background Research}

Waqas and et al [4], with reviewing the Critical Barriers to Implementation of Reverse Logistics in the Manufacturing Industry and showed that The most critical barriers with respect to each category are: high cost of reverse logistics adoption (finance and economics), lack of skilled professionals (knowledge and experience), lack of government supportive policies (law and regulation), poor organizational culture (management), lack of human resources (infrastructure and technology), lack of environmental law awareness (environment), lack of community pressure (market) and company policies (reverse logistics in policy). Overall, the top five barriers found in this study include lack of initial capital, lack of skilled professional in RL, companies' policies against RL, lack of new technologies and information systems, and lack of community pressure. Knowledge about barriers to reverse logistics allows manufacturing companies to prepare a priority list of actions for better implementation of the reverse logistics system. A Case Study of a Developing Country Using fuzzy numbers to describe the desirability of strategies based on Bonisson's methodology and ranking method, using fuzzy multi-criteria models and prioritizing strategic orientation factors and sustainable supply chain initiatives. Identifying Strategic Orienteering Criteria and Sustainable Supply Chain Initiatives, Reverse Logistics and Prioritizing through Fuzzy Multi-criteria Models [5]; Strategic orientation originally stemmed from the market orientation notion, which was a popular means to measure firm performance. According to Manu and Sriram, strategic orientation refers to "how an organization uses strategy to adapt and/or change aspects of its environment for a more favorable alignment [2]." Extended versions focus on customer or technology orientations, and Narver and Slater, argue that strategic orientation is an critical component of profitability for both manufacturing and service businesses, such that an orientation influences business decisions through its effects on business profitability [6].

Zhang, G., \& Zhao, Z. [7] examines Green Packaging Management of Logistics Enterprises. Chang et al [8], In an article, introduced and implemented a multi-criteria decision-making approach based on trust and credit in the supply chain. Initially, they introduced the general trust indices in the true supply chain settings, and designed multidimensional trust and credibility models. Then based on the model of trust and credibility, the multivariate decision-making approach was based on variable weights and the principle of satisfaction. Simulation experiments showed that the proposed model can effectively filter the false ratings of those customers who have been lying and the multi-criteria decision method can help customers make the right decision. In the study of Ronald Yager.[9], the basic characteristics of the fuzzy measurement are first introduced. Then, discusses the Choget integral and discusses its use in finding the accumulation of the collected values of the fuzzy measured values. It is then shown how the integer and the corresponding fuzzy integer can help the structure of multi-criteria decision-making functions and describe how the fuzzy measurement is used to model a specific multi-criteria decision function. Then they look at different fuzzy dimensions and examine the various types of decision-making functions they are allowed to formulate. Finally, they show how to model the linguistic decision-making functions by using fuzzy measures. By engaging in reverse logistics, firms can recycle remanufactured parts or components, as well as dispose properly of those components that cannot undergo remanufacturing or recycling. In turn, they constitute a substantial cost-driving area and may result in greater profitability and customer satisfaction, as well as benefitting the environment [10]. Hsu et al [11], determined the six main criteria for the validity of strategic orientation, strategic orientation, green purchases, green production, packaging, 
and reverse logistics by examining strategic orientation, sustainable supply chain and reverse logistics by factor analysis.

\section{Research Method}

The present research is applied in the context of descriptive research, because the researcher describes the strategic orientation and sustainable supply chain initiatives based on reverse logistics. He intends to identify the components and the main indicators of these variables by prioritizing them in the form of a study A case in the rubber industry.

The sample size in this research was determined by the limited population of the population $(\mathrm{N}=25)$ with the Cochran method for the limited population size of 23 , then by available sampling method and face-to-face sampling (by e-mail and telephone), Their opinion was drawn to participate in the research. By submitting their consent, the questionnaires were sent to their email address or sent to the selected experts by visiting the Dena Tire Factory. In their view, the responses were sent to the researcher's email address after a review of responses and return questionnaires, the final sample size included 14 managers and experts of the rubber industry.

\section{Questionnaire Design}

In this research, two closed questionnaires are used:

Questionnaire A: This questionnaire is designed to screen the indicators of the research variables identified by the library method and the interview, as mentioned in the previous section. In this questionnaire, experts and experts of the rubber industry are asked to screen and identify the main components of strategic orientation factors, reciprocal chain logistics and reverse logistics, and according to six identified dimensions, the proportion of indicators with the subject and dimensions of the research Delphi can be expressed as 0-10. Then components with a geometric mean of less than 6 were excluded from the research process.

Questionnaire B: This questionnaire is designed to prioritize strategic orientation, chain initiatives, and reverse logistics. At this stage, after identifying the components of the strategic orientation factors, sustainable supply chain initiatives and reverse logistics, we use the Fuzzy AHP approach to ranking the components. This questionnaire, which is designed in a pairwise comparison on two levels of components and strategic direction factors, sustainable supply chain initiatives and reverse logistics, is based on verbal variables, which evaluates the significance of criteria and dimensions in relation to each other.

The validity of the tool for data collection in this research after extracting and identifying the main indexes ( 5 indicators) and sub-indicators (28 subcategories) based on the research literature and opinions of experts and experts in the rubber industry (case study of DENA rubber industries) using content validity method Experts confirmed. It should be noted that the validity of some of the indicators in the same research has been confirmed by the factor analysis method. The closest study to this study is the base article, Hsu et al. (2016) confirmed the main indexes by confirmatory factor analysis method.

In this research, the reliability of the questionnaire was used for the Cronbach Alpha coefficient for the initial questionnaire approved by the experts (pilot). Husu et al. [11], using Cronbach's alpha coefficient, have reported the main indicators from 0.89 (for strategic orientation validity) to 0.97 (for green purchases). Also, This research in the field of analysis in order to explain and express relationships and causal models need software that, by obtaining information and their combinations, are able to provide the necessary reports and charts, and by summarizing the data quantitatively and qualitatively using Fuzzy MCDM methods : Include (First, we import the data using Excel, then weigh the AHP method using expert selection software, as well as Topsis Solver ranking) and ultimately achieve successful data analysis and decision making.

\section{Results}

The present study was conducted in two different phases; in the first phase, the strategic indicators and sustainable supply chain initiatives were identified and extracted based on reverse logistics by studying the scientific texts and opinions of experts in the rubber industry. A 5-factor model with 28 sub-criteria for priority Strategic orientations and sustainable supply chain initiatives are based on reverse logistics. Then, in the second phase, we evaluated the dimensions and indexes of the model using the Buckley fuzzy hierarchical analysis method. The components of this research have been extracted by studying a large number of related articles and books in different periods of time, in order to provide dimensions and more comprehensive indicators than previous studies. This research with a semantic approach can create a favorable context for implementing sustainable supply chain management in the industry, especially the rubber industry. Considering the increasing importance of environmental issues as well as paying more attention to this issue, as well as the requirements and rules for considering environmental considerations by industries, attention to the proposed model of research and their priority for the government and stakeholders in terms of the investment priority is very useful. It is also possible to use the results (model and weights) as the basic data of the real environmental problems of the country, to measure the units of the rubber industry and to select sustainable units in the sustainable supply chain, at the Environmental Protection Agency.

The benefits of using the Buckley method in this research include:

1. Adherence to the principles of Professor Saaty

2. The complexity of the calculations

3 . Present relative weight of the criteria by defuzzification the fuzzy weights of the criteria

4. Presenting more realistic weights, according to expert opinion 
In the second phase, based on the results of questionnaire B, by analyzing the fuzzy hierarchy using the Buckley method, the final ranking of the criteria and the final ranking of the sub criteria, regardless of the main criteria, are in accordance with Tables 1 and 2. Finally, the final ranking of strategic orientation factors and sustainable supply chain initiatives were based on reverse logistics, which determined that the best option for green purchasing is the strategic direction and sustainable supply chain initiatives of the sustainable supply chain.

Table 1. Options Ranking.

\begin{tabular}{lll}
\hline Rank & option & Similarity index \\
\hline 1 & Collecting products and packages used by customers & 0.423 \\
2 & Return products to customers & 0.416 \\
3 & Return of products to suppliers & 0.398 \\
4 & Return Package to Customers & 0.932 \\
\hline
\end{tabular}

Table 2. Final weights following criteria.

\begin{tabular}{|c|c|c|}
\hline Rank & Indicators & Weight \\
\hline 1 & Specifications and Specifications Green Design (Sustainable Design Features) (C1) & 0.122 \\
\hline 2 & Packages for reuse or recycling of materials and compatible with nature (D2) & 0.106 \\
\hline 3 & Packing Minimum Material (D3) & 0.74 \\
\hline 4 & Compliance with Stable Regulations (Green) (C3) & 0.72 \\
\hline 5 & Selection and evaluation of suppliers based on sustainability criteria (green) (C4) & 0.41 \\
\hline 6 & Environmental responsibility (A1) & 0.39 \\
\hline 8 & Evaluating the environmental impacts of the product on the basis of the evaluation of the product life cycle (E3) & 0.32 \\
\hline 9 & Partnership (shared) in Sustainable Environmental Standards (Green) (C2) & 0.03 \\
\hline 10 & Participation in green schemes (A2) & 0.029 \\
\hline 11 & Packing with materials and materials (D1) & 0.028 \\
\hline 12 & Innovation culture in the company (B4) & 0.027 \\
\hline 13 & Using images and shapes to develop green plans (A5) & 0.023 \\
\hline 14 & Use labels to indicate the recoverability of the package and its degree of compliance with environmental standards (D4) & 0.022 \\
\hline 15 & Increasing product lifetime based on its highest efficiency and efficiency (E4) & 0.021 \\
\hline 16 & Stable life cycle assessment (green) (B3) & 0.021 \\
\hline 17 & Allocation of resources to promote innovation (B1) & 0.018 \\
\hline 18 & Production planning and process optimization with the goal of reducing waste (E1) & 0.017 \\
\hline 19 & Process and innovation of green product (sustainability) (B2) & 0.016 \\
\hline 20 & Corporate policies promoting green schemes (A3) & 0.014 \\
\hline 21 & Producing products with certainty about their recycling (E2) & 0.009 \\
\hline 22 & Respect for environmental health (A4) & 0.008 \\
\hline
\end{tabular}

\section{Discussion}

According to Tables 1, the best factor of strategic orientation and sustainable supply chain initiatives based on reverse logistics is green purchasing followed by green packaging and according to Tables 2, rubber industry Dena's criteria for green production (in particular, the criteria for "production planning and optimization of waste reduction processes" and "increasing product lifespan based on its highest efficiency and efficiency"), the validity of strategic orientation (especially the criteria for "respect for welfare" (Environmental health) and "company policies for the promotion of green schemes") and the strategic orientation initiative (especially the "process and innovation" criteria Green crop productivity (stable) "," allocation of resources to promote innovation "and" Life Cycle Assessment Sustainable (Green) ") than other measures are in poorer condition. In general, managers and, in particular, traditional green production managers, consider innovation and strategic credibility as sluggish and costly factors and have no economic justification for it.

On the other hand, management commitment and support are the most important factors for the full deployment of a sustainable environmental system, which may be less likely in these industries due to lack of government support and sometimes control laws, unfortunately, management support. For this reason, from the viewpoint of experts in the green rubber industry, it is more important than the other factors, because the green production process reduces companies' resources and energy consumption, reduces the cost of raw materials, produces production, reduces costs Environmental pollution, lower environmental pollution based on green production standards, reducing safety problems and more Appetite, and helps improve the company's image [12]. Hence, green production contributes to the growth of profits and increases market shares and supply chain initiatives. In fact, in the rubber industry due to the use of traditional technologies and processes and the lack of modern technologies, the amount of waste and pollutants is very high and the process of production does not have the ability to reuse waste, therefore, the use of advanced and clean technologies And the ability to 
reproduce and rework is important in achieving environmental goals.

The next factor is green packaging, which confirms other studies, so that Buyukozkan \& Cifci showed that $80 \%$ of environmental impacts could be affected by the design of the product and its subset, packaging [13]. Min \& Galle, suggest greening the costs that companies can spend at the start of the supply chain, with respect to the use of recyclable materials and reuse, which can be considered based on reverse logistics metrics [15]. Although Wu \& Tseng [14], emphasize that environmental impacts will occur throughout the product life cycle, they also consider the life cycle assessment as an indicator used for managing green supply chain management. Application of green design can include the fact that companies can ensure that their products include recyclable and reusable components.

Green packaging can be considered as a subset of green design; Some studies have suggested that green supply chain management components should be developed for companies and their suppliers to have an active and collaborative approach to green packaging for products. To be other studies have provided components for green packaging that are sponsored by the following [16]:

1. Recycled packaging and reuse.

2. Reduce waste by reducing materials used in green packaging

3. Avoid using harmful toxic substances

In a study by Zhang and Xavi [7], green packaging is packed with environmentally-friendly packaging and the likes of nature-friendly materials. According to them, green packaging can be made from natural and plant materials that are reusable and prone to fragmentation Be It also has the least damage to the environment, the health of humans and livestock during its life cycle. In short, green packaging is a suitable packaging that can be reused, recycled or degraded, and does not cause any pollution during human life and the environment, in accordance with the sub criteria of reverse logistics, which is the return of products to Customers, as well as collection, transportation, separation of products and packaging used by customers for recycling, should be considered, can be considered important.

\section{Conclusion}

In this study, using experts from the rubber industry, using fuzzy multi-criteria models, identifying and prioritizing the strategic orientations and sustainable supply chain initiatives based on reverse logistics, the final results showed that the green purchases of the best The factor is the factor of strategic orientation and sustainable supply chain initiatives based on reverse logistics. In this connection, most researchers emphasize the fact that green purchases should be based on reverse logistics criteria, so it can be argued that green purchases should reflect Efforts to reduce, use Reuse and recycling of materials is, therefore, according to Sundram \& et al, the decision to purchase considerable impact on the supply chain sustainable [17].

\section{References}

[1] Ghasemi, Ahmad R., RayatPisheh, Mohammad A. Providing a model for assessing the supply chain sustainability with the meta-composition approach, Journal of Executive Management, 2016, 7 (14): 91-112.

[2] Jasenka Djikanovic \& Mirko Vujosević. A new integrated forward and reverse logistics model: A case study, International Journal of Computational Intelligence Systems, 2016, 9 (1): 25-35.

[3] Ghasemi, Ahmad R., RayatPisheh, Mohammad A. \& Azizi, Javad. Sustainable supply chain. Tehran: A look of knowledge. 2016.

[4] Waqas, M., Qian-li Dong, O., Yuming Zhu and Nadeem, A. Critical Barriers to Implementation of Reverse Logistics in the Manufacturing Industry: A Case Study of a Developing Country, Sustainability 2018, 10 (11), 4202.

[5] Zhu, Q., \& Sarkis, J. The moderating effects of institutional pressures on emergent green supply chain practices and performance. International Journal of Production Research 2007, 45 (18), 4333-4355.

[6] Schniederjans, M. \& CAO, Q. Alignment of operations strategy, information strategic orientation, and performance: an empirical study. International Journal of Production Research, 2009, 47 (10), 2535-2563.

[7] Zhang, G., \& Zhao, Z. Green Packaging Management of Logistics Enterprises. International Conference on Applied Physics and Industrial Engineering, Physics Procedia, 2012, 24 $900-905$.

[8] Chang, L., Ouzrout, Y., Nongaillard, A., Bouras, A., \& Jiliu, Z. Multi-criteria decision making based on trust and reputation in supply chain. International Journal of Production Economics, 2014, 147, 362-372.

[9] Ronald R. Yager. On Viewing Fuzzy Measures as Fuzzy Subsets, Journals \& Magazines, 2016, 24(4): 811-818.

[10] Hsu, C. C., Tan, K. C., Suhaiza H. M. Z., \& Jayaraman, V. Supply chain drivers that foster the development of green initiatives in an emerging economy. International Journal of Operations \& Production Management, 2013, 33 (6): 656-688.

[11] [Hsu, C. C., Suhaiza H. M. Z. Strategic Orientations, Sustainable Supply Chain Initiatives, and Reverse Logistics: Empirical Evidence from an Emerging Market, International Journal of Operations \& Production Management, 2016, 36 (1) $1-45$.

[12] Bhatti, M. A. and Sundram, V. P. K. Business Research. Petaling Jaya, Selangor: Pearson Publication. 2016.

[13] Buyukozkan, G. \& Cifci, G. A novel fuzzy multi-criteria decision framework for sustainable supplier selection with incomplete information. Computers in Industry, 2011, 62 (2): 164-174.

[14] Wu, K. J., \&Tseng, M. L. Evaluation the drivers of green supply chain management practices in uncertainty. Procedia Social and Behavioral Sciences, 2011. 25: 384-397.

[15] Brockhaus, S. Analyzing the Effect of Sustainability on Supply Chain Relationships, 2013. 

Reversed Logistic Through Phase Multi-Criteria Modeled (Dena Shiraz Tire Industry Company)

[16] Laosiri hongthong, T., Adebanjo, D., \& Tan, K. C. Green supply chain management practices and performance. Industrial Management \& Data Systems, 2013, 113(8): 1088-1109.
[17] Sundram, V. P. K., Atikah, S. B., Chandran, G. Supply Chain Management: Principles, Measurement and Practice. kuala lumpur: University of Malaya Press, Kuala Lumpur. Benchmarking: An International Journal, 2016. 